\title{
MATERIAIS DIDÁTICOS NA EAD: mapeamento e análise da produção no Brasil
}

\author{
Janandréa do Espírito Santo, UFF, janandrea.contato@gmail.com \\ Rafaela Bohrz, UFF, rafabohrz@yahoo.com.br
}

\section{RESUMO}

Este artigo apresenta reflexões acerca da utilização dos materiais didáticos na Educação a Distância. Trata-se de uma pesquisa bibliográfica e de campo que pretendeu investigar os materiais utilizados no contexto da educação superior brasileira, sua concepção, produção e distribuição - quer em forma impressa ou multimídia. Inicialmente foi realizado o mapeamento dos recursos através de consulta ao Censo EaD e, como complemento, foi construído um questionário destinado a coordenadores de cursos a distância. Como conclusão da pesquisa, observou-se que as instituições utilizam variados meios de transmitir o conhecimento, adotando materiais diversificados em seus cursos e articulando-os com foco no público-alvo e nas especificidades do curso.

Palavras-chave: Educação a Distância, material didático, Censo EaD.

\section{DIDACTIC MATERIALS IN DISTANCE LEARNING: \\ mapping and the analysis of production in Brazil}

\begin{abstract}
This article presents reflections about Distance Learning didactic materials. This is a bibliographic and field research, which sought to investigate the materials used in Brazilian higher education, their concept, production and distribution - whether in printed or a multimedia form. Initially was mapped the resources through Distance Learning Census consultation and, as a complement, was sent a questionnaire for coordinators of distance courses. As the conclusion of this research, it has been established that the institutions used a variety ways of passing on knowledge, adopting diverse material resources in their courses and articulating it focusing in the target audience and in course specific.
\end{abstract}

Keywords: Distance Learning, didactic materials, Distance Learning Census

\section{INTRODUÇÃO}

O século XXI trouxe mudanças que antes eram inimagináveis. $O$ avanço da tecnologia proporcionou e ainda proporciona melhorias em várias áreas, inclusive à Educação: da tinta e papel para os teclados e telas virtuais, a comunicação se sofisticou, bem como o ato de ensinar e de aprender. Livros viraram e-books, diários em papel transformaram-se em blogs, fotografias deixaram o papel e foram digitalizadas e transpostas para álbuns virtuais, desabafos viraram posts em redes sociais etc. 
Mesmo não sendo fruto desses avanços, a Educação a Distância usufrui das novas tecnologias e oferece aos seus alunos a oportunidade de estudar em qualquer tempo e em qualquer lugar. Contudo, ainda há muito o que superar: barreiras tecnológicas, quantidade de vagas, de polos e, principalmente, qualidade. Sobre este último quesito, é importante ressaltar que o aluno que opta por esta modalidade de ensino tem um perfil diferente do discente que prefere as aulas tradicionais, portanto um curso de qualidade deve conhecer e respeitar essas diferenças. Tal conhecimento e respeito costumam vir embutidos na própria organização do curso, na avaliação e, principalmente, no material didático.

Frente a esse contexto e aos diferentes cursos e personagens envolvidos na modalidade EaD, a demanda por recursos didáticos impressos é elevada, necessitando, portanto, da confecção de materiais que facilitem o trabalho pedagógico. Assim, a pesquisa ora proposta se justifica por investigar materiais didáticos utilizados no contexto da educação superior brasileira, sua concepção, produção e distribuição- quer em forma impressa ou multimídia.

\title{
2. IMPACTOS DO MATERIAL DIDÁTICO NA EAD
}

O material didático é uma ferramenta indissociável à educação, principalmente a distância. A linguagem da teoria híbrida ${ }^{1}$ é característica do nosso contexto atual - a modernidade líquida ${ }^{2}$ - e, como consequência, há a pluralidade de meios de produção, divulgação e interconexão de conteúdo. Nesse sentido, é importante compreender como os materiais didáticos (conteúdo e mídias) são produzidos, transmitidos e recebidos.

Refletir na perspectiva do projeto pedagógico do curso e ao selecionar os textos e elaborar os guias didáticos que servirão de apoio para os alunos é extremamente importante. De acordo com Neder:

\begin{abstract}
ao selecionar os textos que serão trabalhados e, ainda, ao planejar e elaborar os guias didáticos que servirão de apoio para os alunos, os professores, ou a equipe responsável pelo ensino, devem ter muito claros os objetivos do estudo de determinado conteúdo, na perspectiva do projeto do curso e da concepção de currículo adotada. (NEDER, 2009, p.18)
\end{abstract}

Sobre o material didático impresso, Paiva et al. $(2002$, p. 6) afirmam que é necessário "colocá-los em uma linguagem que atinja os alunos que, na maior parte do tempo, realizam seus estudos autonomamente. [...] o tratamento didático pedagógico deve ser uma preocupação constante". Preti completa com os seguintes cuidados:

${ }^{1}$ A linguagem híbrida faz parte da teoria das matrizes de linguagem e pensamento, defendida por Lúcia Santaella. Segundo a autora, independente do suporte, meio e canal de comunicação, todas as linguagens estão alicerçadas em três matrizes fundantes: sonora, visual e verbal.

2 Modernidade líquida é um conceito desenvolvido pelo sociólogo polonês Zygmunt Bauman. Ele justifica o uso do adjetivo líquido, pois líquidos mudam de forma muito rapidamente, sob a menor pressão. Na verdade, são incapazes de manter a mesma forma por muito tempo. 
a) redação clara, objetiva, direta, com moderada densidade de informação; b) sugestões explícitas ao longo do texto (o que é importante e relevante, sugestão de leituras, atividades); c) texto estruturado de maneira que propicie coerência interna ("costura", articulação) e localização fácil da informação (por meio da numeração, destaques, ícones, etc.); d)apresentação clara dos objetivos; e) linguagem simples e científica, ao mesmo tempo; [...]. (PRETI, 2010, p.73)

Além do conteúdo impresso, o material didático pode ser composto por outros recursos, dentre eles estão os multimídia. Filatro (2008, p. 71) e Mattar (2014, p. 106) concordam que a possibilidade de explorar conteúdo em formato multimídia é um dos principais benefícios do aprendizado eletrônico em relação ao aprendizado convencional. Segundo os autores, os seres humanos possuem dois sistemas separados de memória: a verbal e a imagética; o primeiro processaria material visual e o segundo, auditivo. Assim, o processamento de sons e imagens seria diferente em nossa mente. Já o processamento de palavras impressas seguiria "um caminho misto nesse sistema, começando no canal visual/pictórico, mas depois se movendo para o auditivo/verbal" (Mattar, 2014, p.107). A associação de um conteúdo em dois sistemas geraria maior capacidade de recordação, embora o excesso possa ser prejudicial.

Juntamente com estas características cognitivas, os recursos multimídia, por suas particularidades intrínsecas, podem envolver o conhecimento ao entretenimento e lazer (Moran, 1995, p. 01) e devem ser explorados com cautela, sempre integrados ao assunto da aula e tendo como foco os objetivos de aprendizagem. Moran (1995, p. 03) também detalha o modo como os elementos de uma obra audiovisual se relacionam com o processo educacional e apresenta propostas de utilização:

- Sensibilização: o vídeo é utilizado visando a contextualização de um novo tema, de forma a gerar o interesse e despertar a curiosidade do aluno acerca dos assuntos a serem abordados na sequência.

- Ilustração: o vídeo é utilizado como apoio a uma exposição sobre determinado assunto, com o objetivo de ampliar o espaço de ensinoaprendizagem por meio da apresentação de cenários alheios ao ambiente educacional.

- Simulação: o vídeo é usado para demonstrar situações, fatos ou procedimentos cuja realização no ambiente de ensino-aprendizagem é inviável, em função das suas limitações espaço-temporais.

- Conteúdo: o vídeo é empregado para apresentar informações sobre determinado assunto.

- Produção: o vídeo é utilizado para registro e documentação das atividades desenvolvidas em sala de aula.

Sobre a articulação entre as diferentes mídias que integram o material didático, é preciso avaliar muito bem em que momentos cabem materiais produzidos em mídia impressa ou digital, pois depende de cada projeto. O foco no público-alvo, ou seja, no aluno, é fundamental. Além disso, deve ser equilibrado e harmônico para motivar a aprendizagem. Nesse sentido, 
Em cada projeto, é preciso avaliar muito bem em que momentos cabem materiais produzidos em mídia impressa ou digital. O perfil do público ao qual o curso se dirige é um elemento muito importante para a tomada de decisão sobre qual é o melhor material didático e a mídia mais apropriada. (RONDELLI, 2007, p. 02)

Tendo em vista o embasamento teórico aqui apresentado, o presente trabalho se propôs a investigar como os materiais didáticos são utilizados nos cursos a distância, seguindo a metodologia apresentada a seguir.

\section{METODOLOGIA: PESQUISA BIBLIOGRÁFICA E DE CAMPO}

Com objetivo de obter maior diversidade de dados e mais qualidade no estudo, optou-se por usar a pesquisa bibliográfica e de campo. O mapeamento bibliográfico foi feito tendo como base os relatórios finais do Censo da EaD - 2012/2013 e 2013/2014, respectivamente - os quais são investigações que a Associação Brasileira de Educação a Distância (ABED) promove anualmente junto com instituições que praticam com a modalidade a distância. Em relação à natureza de campo, conforme Assis (2009, p.24), uma pesquisa pode ser delineada de várias formas, considerando que há muitas possibilidades de testar hipóteses. Como técnica de coleta de dados foi escolhido o questionário, uma vez que "é a forma mais usada para coletar dados, pois possibilita medir com mais exatidão o que se deseja." (CERVO; BERVIAN; DA SILVA, 2007, p. 53).

Em vista disso para a definição das amostras foi criado um questionário na ferramenta online Google Forms. O formulário foi composto por oito questões de múltipla escolha, que buscavam interrogar sobre o processo de produção do material didático. O público-alvo da pesquisa foram os coordenadores de diferentes cursos de 60 instituições de ensino superior que ofertam aulas a distância. O convite para a participação nesta pesquisa foi enviado através de e-mail, sendo que os contatos dos docentes foram extraídos dos sites institucionais.

A análise dos dados obtidos ocorreu quando se obteve uma amostra significativa de respondentes (55\%). Os dados foram tabulados na própria ferramenta Google Forms e comparados em seus aspectos comuns e divergentes, sempre à luz do aporte teórico levantado na bibliografia utilizada. Tais análises possibilitaram a identificação do diagnóstico e resultados a seguir.

\section{RESULTADOS DA PESQUISA: A RELAÇÃO ENTRE IMPRESSOS E MULTIMÍDIA NA EAD}

\subsection{Produção de material didático impresso}

No levantamento do Censo EaD 2012/2013 foram convidadas 1.200 instituições privadas, públicas, organizações não governamentais (ONGs), entre outras desenvolvedoras de EaD no Brasil, associadas ou não à Associação Brasileira de Educação a Distância (ABED). Contou com 284 respondentes, sendo 231 instituições formadoras, 21 fornecedores de produtos e serviços de EaD e 32 professores independentes. Ao analisar a variável "esquema operacional", verificou-se 
especialmente a presença e uso dos materiais impressos como recurso educacional nas entidades respondentes. Em relação à comparação do recurso "material impresso" com os demais citados no relatório, é possível perceber que seu uso está presente nos diferentes tipos de cursos, comparando-se aos números de outros recursos bem pontuados, tais como o fórum e e-mail. Tal fato demonstra que em torno de $82 \%$ das instituições respondentes utilizam formalmente o recurso impresso em seus cursos. Nota-se ainda que mais de $70 \%$ do conteúdo é desenvolvido por meio de atividades a distância.

No CensoEaD.BR 2013/2014, publicado posteriormente, foram consultadas 309 instituições, entre elas as formadoras em vários níveis (cursos credenciados, livres não corporativos e livres corporativos) e fornecedores de produtos e serviços para este ambiente. Tais respondentes representam por mais de 15 mil cursos e quase 4 milhões de alunos. Na tabela a seguir, é possível verificar o uso de materiais impressos pelas instituições no período em questão.

Tabela 1 - Livros e materiais impressos produzidos para o curso

\begin{tabular}{|c|c|c|c|c|c|}
\hline & \multicolumn{5}{|c|}{ Tipos de cursos/disciplinas EaD } \\
\hline & $\begin{array}{l}\text { Regulamentados } \\
\text { totalmente a } \\
\text { distância }\end{array}$ & $\begin{array}{l}\text { Regulamentados } \\
\text { semipresenciais }\end{array}$ & $\begin{array}{l}\text { Disciplinas } \\
\text { EaD de cursos } \\
\text { presenciais }\end{array}$ & $\begin{array}{l}\text { Livres não } \\
\text { corporativos }\end{array}$ & $\begin{array}{c}\text { Livres } \\
\text { corporativos }\end{array}$ \\
\hline $\begin{array}{l}\text { Instituições } \\
\text { formadoras }\end{array}$ & 71 & 37 & 23 & 34 & 19 \\
\hline $\begin{array}{l}\text { Instituições } \\
\text { formadoras- } \\
\text { fornecedoras }\end{array}$ & 7 & 3 & 5 & 10 & 10 \\
\hline
\end{tabular}

Em relação às instituições formadoras-fornecedoras, nota-se o uso menor dos materiais impressos. Tal fato ocorre também por representarem uma menor quantidade de respondentes no Censo $\operatorname{EaD} e$, ainda, por trabalharem com a modalidade, mas não terem alunos.

Embora a diminuição do uso do recurso impresso seja notória no quadro anterior, cabe ressaltar que, mesmo assim, do total de respondentes da pesquisa, verifica-se que $70 \%$ deles utiliza o material impresso em seus cursos. A fim de comparação, é importante destacar, ainda, que embora os números de usos dos recursos online sejam superiores aos materiais impressos, ainda há um número expressivo desse tipo de oferta.

Os dados referentes aos materiais didáticos impressos (MDI) apontados pelo Censo EaD foram confirmados na pesquisa de campo realizada em julho de 2015. Quando questionados sobre os materiais utilizados nos cursos, os coordenadores participantes da pesquisa responderam da seguinte maneira, representada pelo gráfico $1^{3}$.

\footnotetext{
${ }^{3} \mathrm{O}$ total das porcentagens ultrapassa os $100 \%$, visto que os entrevistados poderiam selecionar mais de uma opção em todas as questões.
} 

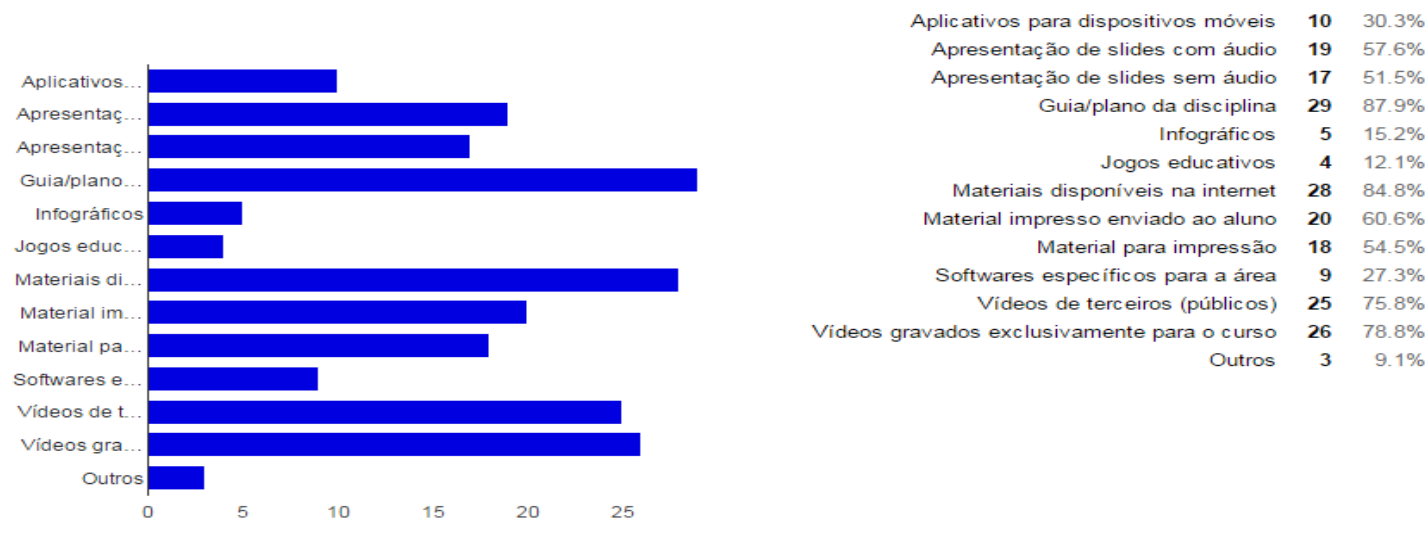

Gráfico 1 - Recursos didáticos utilizados pelas universidades brasileiras

Como visto na fundamentação teórica, os recursos utilizados dividem-se, basicamente, em material impresso/para impressão (com uma leve vantagem do primeiro, ou seja, a maior parte das instituições envia o material didático impresso ao aluno), vídeos (próprios ou públicos, em quase igual porcentagem) e apresentação de slides (com áudio ou sem áudio). Ainda, observa-se que a grande maioria das universidades brasileiras utiliza materiais disponíveis na internet $(84,8 \%)$.

Um dado importante não abordado no Censo, mas revelado na pesquisa de campo é sobre a seleção destes materiais. A grande maioria dos entrevistados afirmou que a escolha acontece durante o planejamento do curso/disciplina (71,9\%) ou durante a construção do material didático (43,8\%). Outras respostas foram: durante a montagem do Ambiente Virtual de Aprendizagem (28,1\%) e durante o andamento das aulas (31,3\%). Já o responsável pela escolha dos materiais é, basicamente, o professor conteudista $(93,9 \%)$, também chamado de professor autor em algumas instituições de ensino. Outros personagens citados foram o designer educacional $(60,6 \%)$, o revisor técnico $(57,6 \%)$, a coordenação pedagógica $(54,5 \%)$ e o tutor $(18,2 \%)$.

Em relação ao conteúdo do $\mathrm{MDI}$, nota-se uma grande ênfase ao texto escrito, pois $81,8 \%$ dos entrevistados apontaram a linguagem dialógica como um dos elementos fundamentais para um material didático eficaz. Quanto aos elementos visuais, os ilustrativos parecem ter preferência aos que contenham conteúdo (42,4\% e $21,2 \%$, respectivamente). Dadas as restrições da pesquisa, não foi possível avaliar o conteúdo do material didático produzido, apenas as afirmações dos entrevistados, o que já traz um panorama suficiente para a presente análise.

\subsection{Produção de materiais multimídia}

Através da análise dos dados do Censo 2012/2013 foi possível perceber a produção de outros materiais além dos impressos. O uso de diferentes recursos multimídia foi identificado tanto nos cursos autorizados/reconhecidos quanto nos livres e o seu perfil pode ser visualizado na tabela a seguir. 
Tabela 2 - Perfil dos recursos educacionais

\begin{tabular}{|c|c|c|c|c|c|}
\hline \multirow{2}{*}{$\begin{array}{c}\text { Recursos educacionais } \\
\text { utilizados nos cursos }\end{array}$} & \multicolumn{5}{|c|}{ Tipos de cursos } \\
\cline { 2 - 6 } & $\begin{array}{c}\text { Não corporativos } \\
\text { Cursos EaD } \\
\text { completos }\end{array}$ & $\begin{array}{c}\text { Disciplinas } \\
\text { EaD }\end{array}$ & Corporativos & Não \\
Códeos curtos & 93 & 39 & 10 & 69 & 47 \\
\hline $\begin{array}{c}\text { Vivativos } \\
\text { (menos de 10 min) }\end{array}$ & 69 & 24 & 5 & 34 & 19 \\
\hline Multimídia em CDBs e dados & 63 & 34 & 9 & 65 & 41 \\
\hline Animação & 61 & 27 & 3 & 32 & 19 \\
\hline $\begin{array}{c}\text { Teleaulas (aulas expositivas } \\
\text { previamente gravadas) }\end{array}$ & 55 & 19 & 5 & 31 & 14 \\
\hline $\begin{array}{c}\text { Vídeos longos } \\
\text { (mais de 10 min) }\end{array}$ & 45 & 22 & 6 & 46 & 24 \\
\hline Jogos & 40 & 17 & 3 & 28 & 15 \\
\hline $\begin{array}{c}\text { Programas de áudio pré- } \\
\text { gravados }\end{array}$ & & & & & 19 \\
\hline
\end{tabular}

Os dados acima apresentados corroboram o que foi percebido na pesquisa de campo, ou seja, a supremacia do vídeo como recurso multimídia na EaD, já apresentado no gráfico 1.

Quanto à função atribuída a esse recurso (cf. MORAN, 1995) e de acordo com o gráfico a seguir, percebeu-se que o vídeo é utilizado pelas instituições principalmente como conteúdo de ensino $(81,8 \%)$, seguido de ilustração $(66,7 \%)$ :

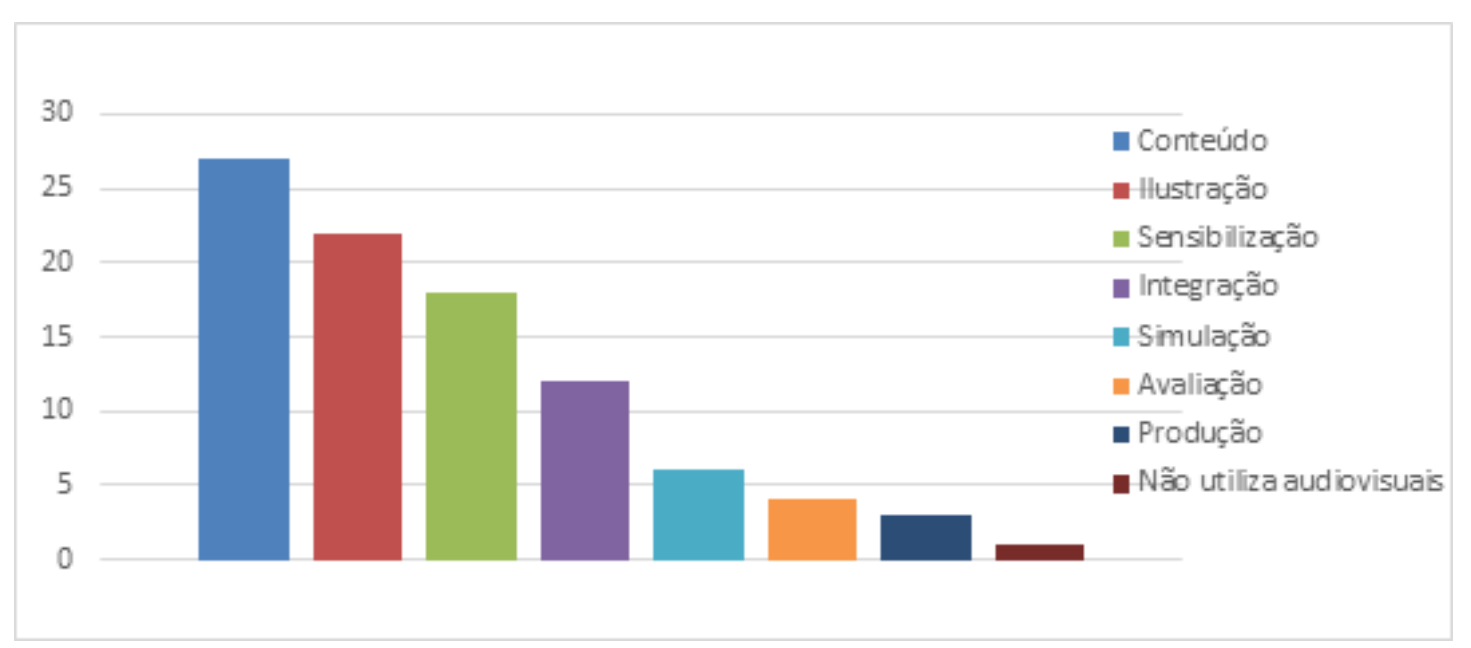

Gráfico 2 - Utilização dos recursos audiovisuais

Tal realidade reflete um posicionamento das universidades alinhado às recentes teorias sobre o assunto. Nesse sentido, a prática pedagógica evolui à medida que as teorias são postas à prova e corroboradas (ou não) pela prática diária. 


\subsection{Articulação entre os recursos didáticos}

É evidente que a qualidade de um curso depende da combinação de vários aspectos, mas, como afirmado anteriormente, é grande a importância do material didático. De acordo com os Referenciais de Qualidade para Educação a Distância, eles devem:

Integrar as diferentes mídias, explorando a convergência e a integração entre materiais impressos, radiofônicos, televisivos, de informática, de videoconferências e teleconferências, entre outros, para favorecer a construção do conhecimento e a interação entre os múltiplos atores. (BRASIL, 2007, p. 14, grifo nosso)

O primeiro passo para a integração das diferentes mídias no material didático é, obviamente, escolher quais mídias serão utilizadas. Para isso, é necessário considerar os objetivos específicos a serem alcançados pelo aluno, dentro de um planejamento que precisa considerar também o modelo de ensino-aprendizagem. Isso se refletiu na pesquisa de campo realizada, uma vez que a grande maioria dos entrevistados afirmou que a escolha dos materiais acontece durante o planejamento ou construção do material didático. Percebeu-se através dela que o principal responsável por fazer esta articulação é o professor autor, durante a construção dos materiais que compõem a disciplina (78,8\%). Já o professor tutor é o responsável por esta tarefa em $36,4 \%$ das instituições.

Levando em conta que a maioria das universidades pesquisadas afirma utilizar o texto (impresso ou para impressão) aliado aos materiais disponíveis na internet conforme analisado no início desta pesquisa -, cabe investigar ainda quais os critérios utilizados para a seleção e articulação dos materiais. Para tanto, foi elaborada uma pergunta à qual deveria ser atribuída uma nota de importância ao quesito, sendo 1 para menos importante e 5 para mais importante. Para fins desta análise, os números foram convertidos aos seguintes conceitos: 1 - nada importante; 2 - pouco importante; 3 - média importância; 4 - muito importante e 5 - extremamente importante.

De acordo com as respostas, a grande maioria dos entrevistados demonstra preocupação com o alinhamento entre os recursos e as especificidades do curso, sendo que $80,6 \%$ consideram extremamente importante, $12,9 \%$ consideram importante e $6,5 \%$ atribuem média importância. Uma surpresa foi quanto à relevância do conteúdo, avaliada da seguinte maneira que pode ser observada no gráfico abaixo.

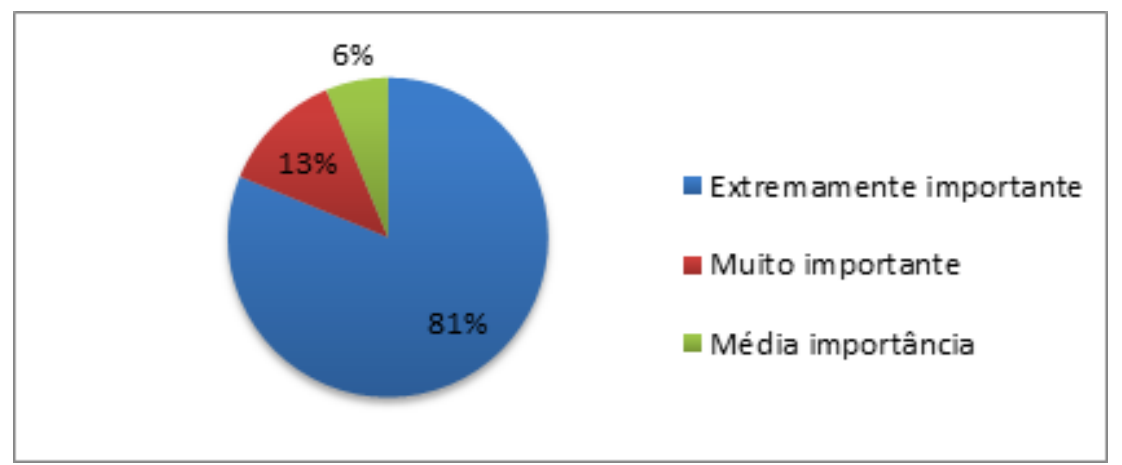

Gráfico 3-A importância do conteúdo do recurso educacional disponível na internet 
O que significa que quase $20 \%$ não dão importância máxima ao conteúdo dos materiais da internet e à sua articulação com os materiais impressos/para impressão. Da mesma forma, a função dos recursos, conforme explicada por Moran e tratada anteriormente, é considerada extremamente importante por $62,5 \%$ dos entrevistados. Além disso, é também nítida a preocupação com os direitos autorais, pois apenas $5 \%$ atribuiu muita importância, todos os demais consideraram esse quesito extremamente importante.

\section{CONCLUSÕES}

Após a realização deste estudo, apresentam-se algumas considerações sobre o tema de investigação proposto, o qual objetivou, ao longo de seu desenvolvimento, a reflexão acerca do impacto dos materiais didáticos e recursos multimídia na Educação a Distância.

Posteriormente ao estudo e a análise das duas últimas edições do Censo EaD, foi possível perceber que o uso dos materiais impressos é, apesar do avanço da modalidade, ainda muito utilizado, oferecendo o conteúdo do curso de uma forma tradicional e transmitindo segurança ao aluno em seu processo de aprendizagem. Os dados aqui representados caracterizam-se, enfim, como indicadores de tendências e de análise macroestrutural do setor educacional.

Em relação à análise da pesquisa de campo, foi possível constatar a relevância dos materiais textuais, sendo a linguagem dialógica considerada como um dos elementos fundamentais para um material didático eficaz. Quanto aos elementos visuais, os ilustrativos parecem ter preferência aos que contenham conteúdo, embora não sejam considerados fundamentais. Entretanto, o potencial pedagógico do uso de imagens, animações, vídeos, áudios e outros recursos visualmente atraentes e com bons níveis de interatividade deveriam ser explorados enquanto elemento de promoção do desenvolvimento cognitivo do aluno (FILATRO, 2008, p. 53). Além disso, a grande maioria dos entrevistados demonstra preocupação com o alinhamento entre os recursos e as especificidades do curso, os perfis dos alunos e do professor, além do conteúdo, do fácil acesso e, unanimemente, dos direitos autorais.

Como afirmado anteriormente, essa pesquisa não teve a ambição de fornecer respostas definitivas para o problema levantado. Por hora, é importante ressaltar a conclusão de que as instituições percebem a necessidade de utilizar variados meios de transmitir o conhecimento e adotam materiais diversificados em seus cursos, conforme as respostas dos entrevistados e o levantamento pelo Censo EaD.

\section{REFERÊNCIAS BIBLIOGRÁFICAS}

ABED. Censo EaD.br: relatório analítico da aprendizagem a distância no Brasil 2013 = Censo EaD.br: analytic report of distance learning in Brazil/[traduzido por Maria Thereza Moss de Abreu]. - Curitiba: Ibpex, 2014. Disponível em: <http://www.abed.org.br/censoead2013/CENSO_EAD_2013_PORTUGUES.pdf>. Acesso em 15 ago. 2015. 
ABED. Censo EAD.br: relatório analítico da aprendizagem a distância no Brasil $2012=$ Censo EAD.BR: Analytic Report of Distance Learning in Brazil/[traduzido por Opportunity Translations]. - Curitiba: Ibpex, 2013. Disponível em: <http://www.abed.org.br/censoead/censoEAD.BR_2012_pt.pdf>. Acesso em 18 ago. 2015.

ASSIS, M. C. Metodologia do Trabalho Científico. 2009. Disponível em: <http://portal.virtual.ufpb.br/biblioteca-

virtual/files/pub_1291081139.pdf> Acesso em: 23 mar. 2015.

BAUMAN, Z. Vivemos em tempos líquidos. Nada é para durar. Depoimento. [24 set. 2010]. Istoé Online. Entrevista concedida a Adriana Prado. Disponível em: <http://www.istoe.com.br/assuntos/entrevista/detalhe/102755_VIVEMOS+TEMPOS+L IQUIDOS+NADA+E+PARA+DURAR>. Acesso em: 27 jul. 2015.

BRASIL. Ministério da Educação e Cultura. Secretaria de Educação a Distância. Referenciais de qualidade para Educação a Distância. Brasília: MEC, 2007. Disponível em: <http://portal.mec.gov.br/seed/arquivos/pdf/legislacao/refead1.pdf>. Acesso em 15 jul. 2015.

CERVO, A. L.; BERVIAN, P. A.; DA SILVA, R. Metodologia Científica. 6. ed. São Paulo: Pearson Prentice Hall, 2007.

FILATRO, A. Design instrucional na prática. São Paulo: Pearson Prentice Hall, 2008.

MATTAR, J. Design educacional: Educação a Distância na prática. São Paulo: Artesanato Educacional, 2014.

MORAN, J. M. O vídeo na sala de aula. Comunicação \& Educação, v.1, n.2, 1995. Disponível em: <http://extensao.fecap.br/artigoteca/Art_015.pdf>. Acesso em: jan. 2014.

NEDER, M. L. C. Planejando o texto didático específico ou o guia didático para a EaD. In: Possari, Lucia Helena Vendrúsculo. Material Didático para a EaD: Processo de Produção./ Lucia Helena Vendrúsculo Possari; Maria Lucia Cavalli Neder. Cuiabá: EdUFMT, 2009.

PAIVA, L. F. R. de et al. Os limites e possibilidades do trabalho e da formação de uma equipe multidisciplinar em Educação a Distância: relato de uma experiência. São Paulo: ABED, 2002. Disponível em: <http://www.abed.org.br/congresso2001/38.zip>. Acesso em: 17 ago. 2015.

PRETI, O. Produção de Material Didático Impresso: orientações técnicas e pedagógicas. Cuiabá: UAB/UFMT 2010, 210p. Disponível em: <http://www.uab.ufmt.br/uUAB/ploads/pcientifica/producao_material_didatico_impr esso_oreste_preti.pdf>. Acesso em: 20 Fev. 2015.

RONDELLI, E. Material didático: interatividade é fundamental. Entrevista. Universo EAD. 2007.2 Disponível em: <http://www.ead.sp.senac.br/newsletter/novembro06/mercado/mercado.htm> Acesso em: 24 fev. 2015.

SANTAELLA, L. Matrizes da linguagem e pensamento: sonora, visual, verbal: aplicações na hipermídia. São Paulo: lluminuras e FAPESP, 2005. 